University of Louisville

ThinkIR: The University of Louisville's Institutional Repository

Electronic Theses and Dissertations

$5-2018$

\title{
Long-term dental outcomes of the professional education preparation program.
}

Samuel D. Petersen

University of Louisville

Follow this and additional works at: https://ir.library.louisville.edu/etd

Part of the Dental Public Health and Education Commons

\section{Recommended Citation}

Petersen, Samuel D., "Long-term dental outcomes of the professional education preparation program." (2018). Electronic Theses and Dissertations. Paper 2919.

https://doi.org/10.18297/etd/2919

This Master's Thesis is brought to you for free and open access by ThinkIR: The University of Louisville's Institutional Repository. It has been accepted for inclusion in Electronic Theses and Dissertations by an authorized administrator of ThinkIR: The University of Louisville's Institutional Repository. This title appears here courtesy of the author, who has retained all other copyrights. For more information, please contact thinkir@louisville.edu. 
$\square$

LONG-TERM DENTAL OUTCOMES OF THE PROFESSIONAL EDUCATION PREPARATION PROGRAM

By

Samuel D. Petersen

B.S., Brigham Young University - Idaho, 2007

\begin{abstract}
A Thesis
Submitted to the Faculty of the School of Dentistry of the University of Louisville In Partial Fulfillment of the Requirements
\end{abstract}

For the Degree of

Master of Science in Oral Biology

Department of Oral Biology

University of Louisville School of Dentistry

Louisville, Kentucky

May 2018 
Copyright 2018 by Samuel D. Petersen

All rights reserved 



\title{
LONG-TERM DENTAL OUTCOMES OF THE PROFESSIONAL EDUCATION PREPARATION PROGRAM
}

\author{
By
}

Samuel D. Petersen

B.S., Brigham Young University - Idaho

A Thesis

May 2, 2018

By the following dŚčç્દ Committee

\begin{tabular}{c}
\hline Dr. Sherry Babbage \\
\hline Dr. Katie Leslie \\
\hline Dr. Faye Jones \\
\hline
\end{tabular}

Dr. Bakeerathan Gunaratnam 


\section{DEDICATION}

This thesis is dedicated to my lovely wife Sheerstie, for her love, encouragement, support and loyal friendship. Also to my beautiful children, Jaylee, Caden, and Aubree who have been so patient while they have been denied of their dad for a season. To Mandee, our newest addition and to my parents who raised the bar on academic achievement and proved that it could be done. 


\section{ACKNOWLEDGEMENTS}

I would like to thank Dr. Sherry Babbage for her support and mentorship as we have learned through this process together. Her commitment to her profession, her community and family is inspiring. I would also offer a special thanks to Dr. Katie Leslie, Dr. Faye Jones and Professor Gunaratnam for their patient teaching, coaching and direction. 


\section{ABSTRACT \\ LONG-TERM DENTAL OUTCOMES OF THE PROFESSIONAL EDUCATION PREPARATION PROGRAM \\ Samuel D. Petersen}

May 2, 2018

Introduction: The Professional Education Preparation Program (PEPP) is a health careers pipeline program for Kentucky pre-health students from Health Professional Shortage Area counties and/or racial/ethnic groups underrepresented in the health professions. The purpose of this study was to determine the demographics of the dental PEPP participants and if, post dental school graduation, they were providing care for underserved patient populations

Methods: PEPP dental graduates $(n=114)$ had been previously identified. Participants were contacted by phone, asked to participate and then mailed a survey. Survey questions covered personal, practice and patient characteristics, procedures performed, insurance accepted and community outreach. Logistic regression analysis was utilized to assess relationships between multiple variables. Additionally, data was compared to American Dental Association (ADA), American Dental Education Association (ADEA) and census data.

Results: Forty-four participants responded. Thirty-four had complete datasets. Approximately 62 percent of PEPP participants reported serving underserved populations. PEPP participant data showed an inclination to accept far higher percentage of Medicaid patients at $42 \%$ of PEPP practitioners accepting Medicaid compared to $9 \%$ of practitioners. The ethnic makeup of their respective patient populations closely mirrored the ethnic makeup of the United States population. The sample size was too small to be statistically efficacious. 
Conclusions: When compared to national averages, PEPP participants treated more Medicaid recipients than the average. Their patient populations were more ethnically diverse than Kentucky's general population. Outcomes were encouraging, as it appeared that the program's graduates were increasing access to care for underserved populations. 


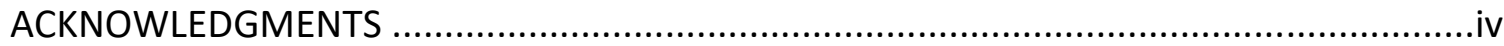

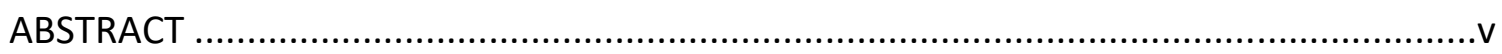

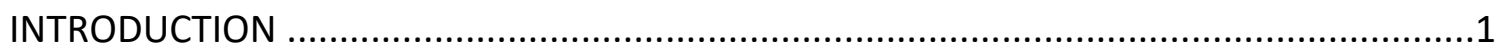

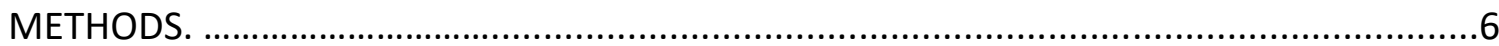

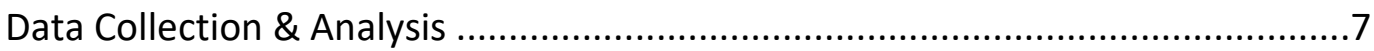

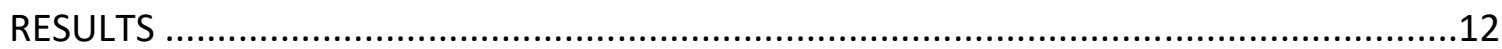

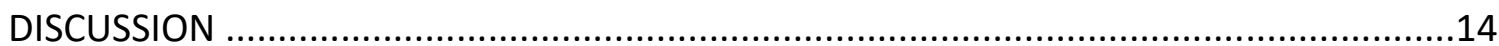

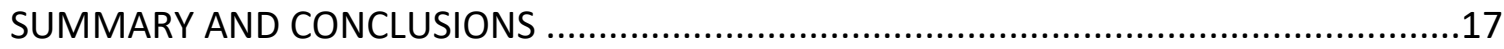

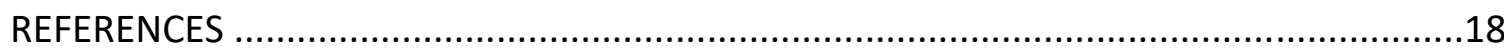

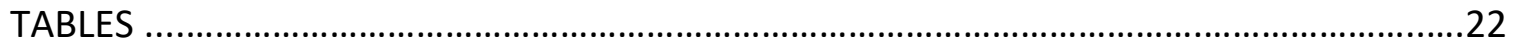

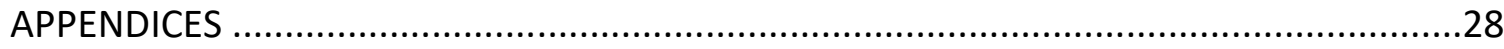

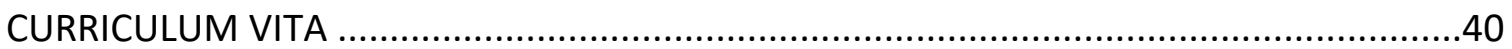




\section{INTRODUCTION}

The Professional Educational Preparation Program (PEPP) has had a long history in Kentucky ${ }^{1,2,3}$. It was first established as a result of The Kentucky General Assembly in 1980. The intention of the program was to increase the number of applicants from underserved communities that apply to and are accepted by the professional health programs, whether that was medicine, dentistry, etc., with the hope that those program participants would establish practices in underserved areas ${ }^{10}$.

There had been prior research that had shown that individuals from underserved areas were more likely to return to the communities they came from, providing the muchneeded care in their community $4,5,6,7,8,9,10,11,12$. With these intentions, the General Assembly created a committee to assess the status of workforce distribution throughout Kentucky counties ${ }^{1}$. The committee found that there were fewer applicants to professional health programs as a ratio per 100,00 people in underserved communities than their non-shortage counterpart ${ }^{1}$. The committee found that individual applicants from underserved areas had poorer grades, poorer acceptance exam scores and poorer acceptance rates than applicants from areas without a shortage of providers ${ }^{1}$.

Armed with their findings the committee created legislation to formally establish the Professional Education Preparation Program. Initially the goals for the program were:

1. "Stimulate an interest in the health professions among students from designated medically underserved areas in the state"1.

2. "Identify high school students and other individuals from such areas who have indicated an interest in and demonstrated potential for, pursuing professional careers" ${ }^{1}$. 
3. “Provide educational enrichment opportunities for such students to prepare themselves for admission to and graduation from professional schools"1.

4. "Provide extramural educational opportunities for underserved areas of the Commonwealth"1.

5. "Identify current health medical and dental students, postgraduate trainees, and residents who are deemed to have realistic potential for recruitment to practice in underserved areas"1.

6. "Provide for the intensive recruitment of such students and postgraduate trainees for practice in underserved areas" 1 .

7. "Provide technical assistance to communities in their recruitment of health professionals"1.

The legislation passed and the program was created under the oversight of the Council on Higher Education. Due to financial restrictions, the program was forced to narrow its focus to the first four items listed above. Oversight for the last 3 items on the list were shifted to the Cabinet for Human Resources and then, in 1990, the responsibility of the last item of recruitment was shifted to the University of Louisville ( $U$ of $L$ ) and the University of Kentucky(UK) ${ }^{1}$.

Two summer workshop programs were developed to implement the goals of the PEPP. The first was a summer program for high school students during the summer prior to entering college. During this 4-week workshop the students stayed on campus at $U$ of L or UK and were mentored by a dental and or medical student. They gained both clinical exposure and academic mentorship, especially in mathematics and science. The second summer workshop was usually during the second summer of an undergraduate program. This workshops' purpose was to prepare students for the Medical College Admission Test (MCAT) and Dental Aptitude Test (DAT) admissions exams. It also provided an opportunity for the future applicants to ask questions of and be directly mentored by faculty and staff that were directly involved in the admissions process of the schools medical and dental 
programs. Program participants were tracked as their academic career developed. Additional tutoring was also available $\mathrm{e}^{1,2,3}$.

There were specific demographics targeted in the PEPP recruiting process. Applications were distributed to schools in counties that were eligible to participate in the program. The program targeted student populations from underserved counties in Kentucky. Applications were sent directly to students from eligible counties that indicated interest in medicine or dentistry on their ACT. Students were then selected based on their American College Test (ACT) scores, high school grade point average (GPA), demonstration of interest in the program, personal statement and their high school curriculum. Applicants were then prioritized based off of their counties Federal Health Professional Shortage Area (HPSA) designation and which county had the fewest participants in the program since it began ${ }^{1}$.

As of 2013, 80 of Kentucky's 120 counties were designated as a HPSA. Of those designated as HPSA's there were three counties, namely: Fulton, Edmonson and Robertson, that did not have a single dentist practicing in the county ${ }^{13}$. According to the same study, certain geographic areas within Jefferson County continued to have a limited concentration of providers. In addition, approximately 150 dental providers were still needed within Jefferson County ${ }^{13}$.

\section{Literature Review:}

There are a number of other pipeline programs in other states throughout the country. For the most part, these programs share goals similar to that of the PEPP here in Kentucky. Many of these have been researched at length with results affirming the effectiveness of the various programs ${ }^{27,28,29,30}$.

Outcomes of the Kentucky PEPP were assessed from 1981-1996 in a comprehensive 15-year report. This report was very thorough and contained much valuable information. However, this report did not include PEP participant demographics. Also, for the purposes of this paper, much of the data is now outdated. 
More recently, outcomes of the PEPP between 1997-2012 were assessed ${ }^{2,3}$. In the study "Academic Outcomes of the Professional Education Preparation Program", the researchers found that out of 1080 PEPP participants that earned a bachelor's degree between 1997 and 2012, 739 (69\%) went on to pursue a graduate or professional degree in any field, 631 (58\%) went on to pursue a graduate or professional degree in the clinical sciences, and 533 (49\%) have earned or are in training for a medical or dental degree ${ }^{2,3}$.

The researchers also found that between 1997 and 2012, there have been 85 PEPP participants that have graduated from dental school with another 52 that were actively enrolled in a dental program ${ }^{2,3}$. At the time of this study, there were 114 PEP program participants identified that had graduated from dental school and who were probably currently practicing dentistry. It was this group that was targeted for the study ${ }^{2,3}$.

In 2013, a cross-sectional study was published that was conducted by researchers at the University of California, San Francisco School of Dentistry to assess the effectiveness of a post-baccalaureate pipeline program designed to increase the enrollment of students from underserved communities, not dissimilar from the PEPP here in Kentucky ${ }^{14}$. The authors of the California study were contacted and shared their instrument. The instrument was modified to serve as the basis for the survey instrument used in this study ${ }^{14}$.

Up to the time of this study, there had not been a specific assessment of the longterm dental outcomes of the PEPP. In past PEPP studies specific outcomes focused more on medical providers, sometimes grouping dental providers into the aggregate of primary care providers. The goal of this study was to assess the long-term outcomes of the PEPP in regards to dental practitioners specifically. Specifically, the aim of this study was to assess the demographics of the individual dental PEPP participant, their practice locations, patient base, practice methods, modes of payment and community outreach and service. The hope was to shed more light on the behavior or tendencies of PEPP participants after graduation from dental school and if, as related to dentistry, the PEPP 
was succeeding in its' goal to increase access to care in underserved counties in the commonwealth of Kentucky. 


\section{METHODS}

The type of study that was selected was a cross-sectional survey. This research design was chosen in part because of its ease, time and cost. It was also chosen because the survey questions were designed after a similar cross-sectional study assessing a similar program in California ${ }^{14}$. In order to increase the strength of this study, the survey results were compared to nationally available statistics with similar metrics. These national statistics were used, to some degree, as a control for this study. The survey was vetted and amended for our purposes. Some additions were also made with the hope that the information could prove to be useful segues for future research.

\section{Sample}

This study was approved by the University of Louisville Institutional Review Board (IRB) and determined to be exempt as human subjects research. The sample used for this study included the PEPP participants identified in a prior study that have graduated from dental school and who are likely to be currently practicing dentistry $(n=114)^{2,3}$. Valid contact information was identified or found via alumni records, public licensure searches, publicly available White Pages and Google searches $(n=97)$. Less than half of the participants surveyed responded $(n=44)$.

\section{Participants}

The outcomes of the PEPP between 1980 and 1996 were assessed in a 15-year report ${ }^{1}$. During a follow up study assessing the outcomes of the PEPP between 1997 and 2011, the researchers found that there have been 1313 PEPP participants during that time $e^{2,3}$. Of those 1313 participants 114 went on to complete graduate training at a dental school and are now licensed to practice dentistry ${ }^{2,3}$. These participants were intimately aware of what the Professional Education Preparation Program was, having 
successfully navigated the summer workshops, subsequent mentorship and acceptance into a professional dental program. The participants were called on the phone to verify correct contact information and to see if they would be willing to participate in the study by answering and returning the 40-question survey instrument. After which a survey was mailed to the address that had been confirmed during the phone call. Of the 97 contacted, 44 voluntarily filled out and returned the survey. Of the 44 returned surveys, 34 had complete data sets.

\section{Data Collection and Analysis}

Initially 114 potential study participants were identified ${ }^{2,3}$. These former PEPP participants had gone on to complete undergraduate work, were accepted into and successfully completed a graduate dental program between 1997 and 2011. Resources, including Alumni records, public licensure searches, Google searches and public White Pages searches, were utilized to find current contact information. Of the 114, 97 former PEPP participants contact information was found.

After finding appropriate contact information, each person was contacted over the phone and informed of the survey and its' purpose and they were asked if they would be willing to participate. The study participant was then mailed a copy of the survey with the preamble form attached. If the survey was not returned within 4 weeks another survey was mailed out to the study participant. For each survey sent out, a random number was assigned between 1 and 97 so that the person surveyed could maintain anonymity once the survey was returned.

With permission, the survey instrument utilized in this study, was largely derived from the survey instrument used by researchers at The University of California School of Dentistry $^{14}$. In their study, the researchers at The University of California School of Dentistry aimed to assess the long-term outcomes of their post-baccalaureate dental pipeline program ${ }^{14}$. The questionnaire was modified for this study and gathered information from 4 categories. The survey was divided into sections. The first section 
focused on the PEPP participants themselves, their ethnic background, socioeconomic background, languages spoken, current debt load and the education level of their parents. An example question is as follows:

How much debt did you have upon graduating from dental school?
A. $\$ 1-\$ 30,000$
B. $\$ 30,001-\$ 74,999$
C. $\$ 75,000-\$ 150,000$
D. $150,001-\$ 300,000$
E. Other amount (Please specify):
F. None

The second set of questions focused on PEPP participants' patient demographics. What were the patients' ethnic backgrounds, what were the patients' primary languages spoken, what were the patients' primary methods of payment? An example question is as follows:

Please estimate the composition of your patients' coverage by payer type in your PRIMARY practice.

(Total should add up to $100 \%$ )

Private Payer:

Insurance:

Medicaid:

Pro-bono/Reduced Fee:

Total:

The third set of questions aimed to collect geographic and demographic information regarding the PEPP participants' office, how many offices, in what type of town, how 
many employees did they have, where did the employees receive their training and what type of dental procedures were primarily performed. An example question is as follows:

Where are you practicing NOW?
A. Large city (Population 500K or more)
B. Suburb of large city
C. City of moderate size $(50 \mathrm{~K}-500 \mathrm{~K})$
D. Suburb of moderate sized city
E. Small city $(10 \mathrm{~K}-50 \mathrm{~K}$ other than a suburb)
F. Town $(2,500-10,000$ other than a suburb)
G. Small town (population less than 2,500)
H. Rural/Unincorporated area
Other (Please specify)

Lastly, the fourth set of questions aimed to assess the PEPP participants' level of outreach and mentorship in their respective communities. An example question is as follows:

How would you describe your level of involvement in mentorship of students interested in the health professions?
A. Very involved
B. Involved
C. Somewhat involved
D. Not very involved

The results of the 40-question survey were recorded in Microsoft Excel. (The full survey instrument can be found in the Appendix.) Once the results were recorded, they were evaluated for complete responses. Of the 44 surveys returned, 10 were missing data 
and 34 were complete. The data was then reformatted to binary to enable logistic regression analysis.

\section{Logistic Regression Analysis:}

A logistic regression analysis is useful when assessing the relationship between multiple variables. This type of analysis is usually utilized as a way of describing the relationship between multiple independent variables and a binary response variable ${ }^{15}$. This method of analysis was chosen to see test the relationship between the many variables present in the study.

The small number of complete datasets creates an issue. Based on the work of Peduzzi et al. (1996) the following guideline for a minimum number of cases to include in the study can be suggested: $N=10^{*} k / p^{16}$. In this case, the number of regression coefficients is $k=3$. And the number of "Yes" responses to the question, "Do you work with an underserved population?" divided by the total amount of responses is our probability or $\mathrm{p}=0.36$. $\mathrm{N}=10 * \mathrm{k} / \mathrm{p}$, which means $\mathrm{N}=83$ would be the ideal for this study. Our study, however, only had $\mathrm{N}=34$.

Knowing that our data set was limited, the logistic regression analysis showed that the variables USPS (Were you interested in working with an underserved population after dental school? (Yes = 1, No = 0)), Insurance (Please estimate the composition of your patients' coverage by payer type in your PRIMARY practice) and Medicaid (Please estimate the composition of your patients' coverage by payer type in your PRIMARY practice) were significantly influenced with the response variable USP (Do you work with an underserved population? $($ Yes $=1$, No $=0)$ ).

$$
\log (p / 1-p)=1.593+0.018 * \text { USPS }-0.026 * \text { Insurance }+0.002 * \text { Medicaid, where } p \text { is }
$$

probability of work with underserved population. The sensitivity and specificity of the model are 0.904 and 0.769 respectively. 
The sensitivity approximated a 90\% chance PEPP participants would accept Medicaid if they indicated they wanted to work underserved population upon completing dental school.

The specificity approximated a $76 \%$ chance one could identify those that would not accept Medicaid if they indicated the PEPP participant indicated they did not want to work with underserved populations after dental school.

In essence, PEP participants that wanted to work with an underserved population accepted Medicaid.

National Statistical Comparison:

Beyond the logistic regression analysis, some interesting data was available by way of comparing the datasets from PEPP participants with National statistics available through the American Dental Education Association (ADEA) and the American Dental Association (ADA) Survey Center. Where possible, these national averages were used as a benchmark when similar metrics of the PEPP participants' data was compared. 


\section{RESULTS}

The first set of questions focused on the demographics of the PEPP participants themselves. When comparing PEPP data to the data published in the ADEA report, it was found that the ethnic makeup of PEPP participants was much less ethnically diverse, $82 \%$ White, 9\% Black/African American and Other races only made up 9\% of the PEPP participants. Graduating seniors of 2016 were made up of 51\% White, 5\% Black/African American and $44 \%$ Other. (Table 1 )

PEPP participants' parental education levels, in reference to Bachelors and Graduate level training, were substantially lower than the average graduate of 2016 . For PEPP participants, there were a substantially higher percentage of respondents claim that their parents attended "some college" or less than a bachelor's degree. Parental education of both PEPP participants and the Class of 2016 had fairly similar percentages in terms of 1 parent that had only a High school or less education level. Where fathers of PEPP participants' had a much greater percentage of having a high school or less education level ${ }^{17}$. (Table 2 ).

PEPP participants spoke mainly English, with only $2 \%$ having a first language other than English and 6\% speaking another language, in addition to English but equally well. (Table 3)

Upon graduating from dental school, approximately 22\% of PEPP participants had between 150,001-300,000 dollars in debt and 67\% had over 300,001 dollars in debt. Approximately $36.10 \%$ of the graduating class of 2016 , on average, had between 150,000 dollars and 299,999 thousand dollars in debt and $33.90 \%$ had debt 300,000 or over ${ }^{17}$. (Table 4) 
Based on the comparisons in Table 5, it was difficult to get a sense if there is much of a difference in the demographic/geographic location of where practitioners end up practicing $^{17}$. (Table 5)

PEPP participant data showed an inclination to accept far higher percentage of Medicaid patients at $42 \%$ of PEPP practitioners accepting Medicaid compared to $9 \%$ of practitioners according to the survey published by the ADA in $2009^{14,20}$. Sixteen percent of PEPP participants' patients were made up of those paying with private insurance, a much smaller number than the average $63 \%$ of private practitioners' patients. This was consistent with the findings of the logistic regression analysis. (Table 6)

Though the ethnic origin of PEPP participants were largely White, the ethnic makeup of their respective patient populations mirrored more closely the ethnic makeup of the United States population, in almost every area except that of Asian populations ${ }^{14,20,21}$. (Table 7)

Approximately $66 \%$ of PEPP participants were involved in some kind of outreach since dental school. Roughly $36 \%$ of participants were "involved" to "very involved" in mentorship for minorities or disadvantages students. Roughly $31 \%$ were "involved" to "very involved" in mentorship for students interested in health professions. Around 60\% of PEPP participants reported being "satisfied" or "very satisfied" with the degree of mentorship and outreach they were involved in. (Table 8)

Of the 44 respondents, 26 provided zip codes in Kentucky where their primary practice is located and where they were currently practicing. Of those $26,19 \%$ were practicing in Kentucky counties currently designated as HPSA's. Seventeen of the respondents provided zip codes for their primary place of practice out of state. (Table 9) 


\section{DISCUSSION}

The logistic regression statistical analysis was limited by the small size of our sample, which means, inherently, the data could not be viewed as definitive or reliable. Further the results did not reveal any findings that were hidden by applying simple common sense. It was found that there was a high degree of relation between the participants that accepted Medicaid and the response variable that indicated the PEPP participant wanted to work with underprivileged populations after dental school. In essence, those PEP participants that wanted to work with an underserved population after dental school accepted Medicaid in their practice.

The PEPP dataset was compared to the most recently available data, published by the ADEA on the dental school graduating class of $2016^{17}$. It was important to note that the cross-sectional comparison of both datasets, though useful in getting an idea of what value the PEP program may have been adding to the community, were not case matched and the instrument utilized to collect the national data was dissimilar to the one used for this study. As such, the data comparisons were not as accurate as they otherwise would have been had they been compared to a case-matched control group with the same survey instrument. In some instances, there was no available data that could be compared to the PEPP data set.

It was found that the $82 \%$ of the PEPP participants were white and $9 \%$ were African American, compared to the graduating class of 2016 , which was approximately $51 \%$ white and 5\% African American. The ethnic makeup of the PEPP program participants largely mirrored U.S. census data that said $88 \%$ of Kentucky's population was white and $8.3 \%$ of the population was African American ${ }^{13}$. When considering 
underserved communities within the state of Kentucky, it is important to bear in mind that within the state of Kentucky, especially in Eastern Kentucky and Appalachia, there are many communities that, though largely white, are among some of the poorest and most uneducated populations in the country ${ }^{25}$. Many of these populations are vastly underserved and due to their geographic locale, continue to be underserved.

This theme remained constant when data about the PEPP participants' parental education was compared to the national averages. In most cases, PEPP participants' parents were less educated. The designation of Parent 1 and Parent 2 in the national data set made comparing the PEPP dataset more ambiguous since it was unclear which parent we were comparing to.

As stated earlier, based on the comparisons in Table 5, it was difficult to get a sense if there was much of a difference in the demographic/geographic location of where practitioners end up practicing. It appeared that, for the most part, PEPP participants were distributed similarly to national averages in regards to what type of a city/geographic location they were practicing in.

When it comes to debt, it appeared that the PEPP counterparts tend to have more debt when compared to the national averages. But again, this data would be better compared to the local dental school populations and their average debt coming out of school. This data would also be better matched to the year or range of years the PEP participants graduated in as tuition rates have continued to rise significantly year over year $^{26}$.

It is interesting to note that, though the PEPP participants were largely ethnically white and African American, the patient populations of the PEPP participants mirrored more closely, on average, that of the ethnic makeup of the national population.

HPSA designations have constantly changed depending on the need of the area in the state. The data utilized when the study commenced indicated that there were over 81 dental HPSA's in Kentucky as of $2013^{3}$. At the conclusion of this study, the data 
provided by the Kentucky department of Health indicated that there were currently 41 counties in Kentucky designated as dental HPSA's. Comparing the practice locations of graduates between 1996 and 2011 to HPSA county designations in 2018 was not a fair representation of where these individuals decided to practice at the time. It would be more accurate to see if PEPP participants were practicing in a county that was designated an HPSA at any point during 1996 to 2011 and possibly a few years after 2011 as some providers could have still been in the process of setting up their primary practice. It would also be beneficial to consider the HPSA designations of the out-of-state county's PEPP participants were practicing in, since this information was not obtained.

The PEP program was primarily designed to help close the access to care disparities here in Kentucky. However, it appeared as though participants were more inclined to serve underprivileged populations independent of practice location. Due to the small sample size, it was not possible to statically substantiate this claim.

In retrospect, there are a number of things that could have been done to increase the effectiveness of the study. The PEPP participant data could have been matched to a control group by age, gender, ethnicity, year graduated and even school attended. Having a case based control such as this would have provided a clearer picture and a much more accurate comparison as to whether or not the program and program participants influenced the outcomes. Due to limitations on resources and time, these options, as they presented themselves during the study, were not ultimately pursued.

Further it would be interesting to see an economic impact study done on the jobs created by these PEP medical and dental providers. Many health providers employ individuals from their own communities. This job creation and the ripple effect it has on underserved communities would be valuable information when considering the viability of pipeline programs like the PEPP. 


\section{CONCLUSION}

It was difficult to draw any definitive conclusions with the small sample size. This was an obvious limitation to the study. However, the logistic regression analysis results could serve as a future model in predicting pipeline participants that are most likely to serve Medicaid recipients. Overall, it appeared as though PEPP dental graduates served a more underprivileged patient base than the average dental school graduate. When compared to national averages PEPP participants treated more Medicaid recipients than the average dental student. PEPP participants' patient population was more ethnically diverse than the general population of the state of Kentucky. The outcomes were encouraging, as it appeared that the program's graduates were increasing access to care for underserved populations. Unfortunately, the Professional Education Preparation Program was defunded during the final stages of this study. Perhaps additional study is warranted in the event that the program is revived or restructured for the benefit of future Kentucky medical and dental providers. 


\section{REFERENCES}

1. Crump, Rebecca; Professional Education Preparation Program 1981-1996 Fifteen Year Report

2. Katie F. Leslie, MS; V. Faye Jones, MD, PhD; Craig Ziegler, MA; Amanda B. Chism, MD; Michael L. Rowland, PhD; carol L. Elam, EdD; Carol Leslie Snyder, MA; From Pipeline to Physician: Practice Outcomes of the Professional Education Preparation Program. Journal of the Kentucky Medical Association Nov 2014; Vol $112,245-251$

3. Amanda B. Chism, MD; Katie F Leslie, MS; Craig Ziegler, MA; V. Faye Jones, MD PhD, From Pipeline to Physician: Practice Outcomes of the Professional Education Preparation Program. Journal of the Kentucky Medical Association Nov 2014; Vol $112,253-258$

4. Bach PB, Pham HH, Schrag D, Tate RC, Hargraves; Primary care physicians who treat blacks and whites. JL N Engl J Med. 2004 Aug 5; 351(6):575-84.

5. Lupton K, Vercammen-Grandjean C, Forkin J, Wilson E, Grumbach K.; Specialty choice and practice location of physician alumni of University of California premedical postbaccalaureate programs. Acad Med. 2012 Jan; 87(1):115-20.

6. Cregler LL, McGanney ML, Roman SA, Kagan DV; Refining a method of identifying CUNY Medical School graduates practicing in underserved areas. Acad Med. 1997 Sep; 72(9):794-7. 
7. Rabinowitz HK, Diamond JJ, Veloski J, Gayle JA.; The impact of multiple predictors on generalist physicians' care of underserved populations. American Journal of Public Health. 2000;90(8):1225

8. Polsky D, Kletke PR, Wozniak GD, Escarce JJ.; Initial practice locations of international medical graduates. Health Services Research. 2002;37(4):907-928.

9. Mertz E, Jain R, Breckler J, Chen E, Grumbach K.; Foreign versus domestic education of physicians for the United States: A case study of physicians of South Asian ethnicity in California. J Health Care Poor Underserved. 2007;18(4):984-993.

10. Ko M, Heslin KC, Edelstein RA, Grumbach K.; The role of medical education in reducing health care disparities: The first ten years of the UCLA/Drew Medical Education Program. J Gen Intern Med. 2007;22(5):625-631

11. McDougle L, Way DP, Rucker YL.; Survey of care for the underserved: A control group study of practicing physicians who were graduates of the Ohio State University College of Medicine Premedical Postbaccalaureate Training Program. Academic Medicine. 2010;85(1):36-40

12. Keith SN.; Role of minority providers in caring for the underserved. J Health Care Poor Underserved. 1990;1(1):90-95

13. Commonwealth of Kentucky. Health care workforce capacity report. 2013: http://healthbenefitexchange.ky.gov/Documents/KY\%20Healthcare\%20Workfor ce\%20Capacity\%20Report\%20FINAL\%205_28_13.pdf

14. Cynthia D. Wides, MA; Harvey A. Brody, DDS, Med; Charles J. Alexander, PhD; Stuart A. Gansky, PhD; Elizabeth A. Mertz, PhD, MA; Long-Term Outcomes of a Dental Postbaccalaureate Program: Increasing Dental Student Diversity and Oral Health Care Access. J Dent Educ. May 2013; 77(5): 537-547

15. Daniel, Wayne W., Cross, Chad L.; Biostatistics A Foundation for Analysis in the Health Sciences, edition 10. Chapter 10 Multiple Regression and Correlation, pages 489-538 
16. Peduzzi P, Concato J, Kemper E, Holford TR, Feinstein AR; A simulation study of the number of events per variable in logistic regression analysis. Journal of Clinical Epidemiology 49:1373-1379.

17. Wanchek, Tanya, Cook, Bryan J., Valachovic, Richard W.; Annual ADEA Survey of Dental School Seniors 2016 Graduating Class. Journal of Dental Education May 2017, 81 (5) 613-630; DOI: https://doi.org/10.21815/JDE.016.027

18. Wells A, Brunson D, Sinkford JC, Valachovic RW.; Working with dental school admissions committees to enroll a more diverse student body. J Dent Educ. 2011; 75(5):685-95

19. Brunson WD, Jackson DL, Sinkford JC, Valachovic RW.; Components of effective outreach and recruitment programs for underrepresented minority and lowincome dental students. J Dent Educ. 2010; 74(10 Suppl):S74-86.

20. American Dental Association. Survey Center. 2008 survey of dental practice: characteristics of dentists in private practice and their patients. Chicago: American Dental Association; 2009.

21. U.S. Census Bureau. 2008 American community survey one-year estimates. Washington, DC: U.S. Census Bureau; 2008.

22. Thomson WA, Ferry P, King J, Wedig CM, Villarreal GB.; A baccalaureate-MD program for students from medically underserved communities: 15-year outcomes. Acad Med. 2010; 85(4):668- 74.

23. Davidson PL, Nakazono TT, Carreon DC, Bai J, Afifi A.; Practice plans of dental school graduating seniors: effects of the pipeline program. J Dent Educ. 2009; 73(2 Suppl): S283-96.

24. https://www.census.gov/quickfacts/KY Census Data 2016 
25. Electra D. Paskett, James L. Fisher, Eugene J. Lengerich, Nancy E. Schoenberg, Stephenie K. Kennedy, Mary Ellen Conn, Karen A. Roberto, Sharon K. Dwyer, Darla Fickle, Mark Dignan; Disparities in Underserved White Populations: The Case of Cancer-Related Disparities in Appalachia; Oncologist. 2011 Aug; 16(8): 10721081.

26. McMahon, Timothy; College Tuition and Fees vs Overall Inflation. 2012, inflationdata.com

27. Smith SG, Nsiah-Kumi PA, Jones PR, Pamies RJ; Pipeline programs in the health professions, part 1: preserving diversity and reducing health disparities. J Natl Med Assoc. 2009 Sep;101(9):836-40, 845-51.

28. Smith SG, Nsiah-Kumi PA, Jones PR, Pamies RJ; Pipeline programs in the health professions, part 2: the impact of recent legal challenges to affirmative action. $J$ Natl Med Assoc. 2009 Sep;101(9):852-63.

29. Holden, L., Rumala, B., Carson, P., \& Siegel, E. (2014). Promoting careers in health care for urban youth: What students, parents and educators can teach us. Information Services \& Use, 34(3-4), 355-366. http://doi.org/10.3233/ISU140761

30. Boateng BA, Thomas BR.; Underrepresented minorities and the health professions pipeline. Acad Med. 2009 Jan;84(1):6-7. doi: 10.1097/ACM.0b013e31819015d0. 
TABLES

\begin{tabular}{|c|c|c|c|}
\hline \multicolumn{4}{|l|}{ Table 1} \\
\hline $\begin{array}{l}\text { Graduating Seniors }(n= \\
6751 \text { ) }\end{array}$ & & $\begin{array}{l}\text { PEPP Participants }(n= \\
\text { 44) }\end{array}$ & \\
\hline White & $51 \%$ & White & $82 \%$ \\
\hline Black/African American & $5 \%$ & Black/African American & $9 \%$ \\
\hline Other & $44 \%$ & Other & $9 \%$ \\
\hline
\end{tabular}

\section{Table 2}

Parents' education level of $\mathbf{2 0 1 6}$ graduating seniors Compared to PEPP Participants Parents

Parents' education level of $\mathbf{2 0 1 6}$ graduating seniors 17

\begin{tabular}{|c|c|c|c|c|}
\hline Level of Education & $\begin{array}{l}\text { Parent } 1 \\
(4,474 \\
\text { respondents) }\end{array}$ & $\begin{array}{l}\text { Combined } \\
\text { Categories }\end{array}$ & $\begin{array}{l}\text { Parent } 2 \\
(4,466 \\
\text { respondents) }\end{array}$ & $\begin{array}{l}\text { Combined } \\
\text { Categories }\end{array}$ \\
\hline $\begin{array}{l}\text { High school graduate } \\
\text { or less }\end{array}$ & $18.40 \%$ & $18.40 \%$ & $19.80 \%$ & $19.80 \%$ \\
\hline $\begin{array}{l}\text { Associate degree or } \\
\text { certificate }\end{array}$ & $6.70 \%$ & & $11.60 \%$ & \\
\hline $\begin{array}{l}\text { Less than a bachelor's } \\
\text { degree }\end{array}$ & $3.70 \%$ & $10.40 \%$ & $6.90 \%$ & $18.50 \%$ \\
\hline Bachelor's degree & $27.50 \%$ & $27.50 \%$ & $34.30 \%$ & $34.30 \%$ \\
\hline Master's degree & $16.20 \%$ & & $15.20 \%$ & \\
\hline $\begin{array}{l}\text { Doctorate or } \\
\text { professional degree }\end{array}$ & $26.70 \%$ & $42.90 \%$ & $10.60 \%$ & $25.80 \%$ \\
\hline Unknown & $0.70 \%$ & & $1.50 \%$ & \\
\hline
\end{tabular}

Parents' education level of 1997-2011 PEPP

Participants

Level of Education (respondents 44)

Below High School

High School

\begin{tabular}{|r|} 
Mother \\
$(n=44)$ \\
\\
$2.30 \%$ \\
$15.90 \%$
\end{tabular}

Father $(n=44)$

$6.80 \%$

$29.50 \% \quad 36.30 \%$ 


\begin{tabular}{|l|l|l|l|l|} 
Some College & $31.80 \%$ & $31.80 \%$ & $20.50 \%$ & $20.50 \%$ \\
Bachelors & $22.70 \%$ & $22.70 \%$ & $15.90 \%$ & $15.90 \%$ \\
Graduate & $27.30 \%$ & $27.30 \%$ & $27.30 \%$ & $27.30 \%$ \\
\hline
\end{tabular}

\begin{tabular}{|l|r|r|}
\hline \multicolumn{3}{|c|}{ Table 3} \\
Lnglish and other language abilities of PEPP program participants \\
\hline Language & \multicolumn{1}{c|}{ Number } & Percentage \\
\hline Speak English & 43 & $91 \%$ \\
Speak another primary language and English equally & & \\
well & 3 & $6 \%$ \\
Speak a non-English primary language & 1 & $2 \%$ \\
Total & 47 & $100 \%$ \\
\hline
\end{tabular}

\begin{tabular}{|c|c|c|c|c|c|}
\hline $\begin{array}{l}\text { Table } 4 \\
\quad \text { Level of deb }\end{array}$ & $\begin{array}{l}\text { of 1996-20 } \\
\text { School con }\end{array}$ & $\begin{array}{l}1 \text { PEPP pa } \\
\text { pared to g }\end{array}$ & $\begin{array}{l}\text { ticipants upon grac } \\
\text { raduating class of } 2\end{array}$ & $\begin{array}{l}\text { ating from } \\
6^{17}\end{array}$ & Dental \\
\hline Level of Debt & Number & Percent & Level of Debt & Number & Percent \\
\hline No debt & 0 & $0 \%$ & No debt & 683 & $16.30 \%$ \\
\hline$\$ 1-30,000$ & 1 & $2 \%$ & Up to $\$ 49,999$ & 154 & $3.70 \%$ \\
\hline$\$ 30,001-74,999$ & 2 & $4 \%$ & $\$ 50,000-\$ 99,999$ & 156 & $3.70 \%$ \\
\hline$\$ 75,000$ & & & $\$ 100,000-$ & & \\
\hline 150,000 & 2 & $4 \%$ & $\$ 149,999$ & 267 & $6.40 \%$ \\
\hline$\$ 150,001-$ & & & $\$ 150,000-$ & & \\
\hline 300,000 & 10 & $22 \%$ & $\$ 199,999$ & 356 & $8.50 \%$ \\
\hline & & & $\$ 200,000-$ & & \\
\hline$>\$ 300,001$ & 30 & $67 \%$ & $\$ 249,999$ & 577 & $13.70 \%$ \\
\hline & & & $\$ 250,000-$ & & \\
\hline Total Number & 45 & & $\$ 299,999$ & 582 & $13.90 \%$ \\
\hline & & & $\begin{array}{l}\$ 300,000- \\
\$ 349,999\end{array}$ & 478 & $1140 \%$ \\
\hline & & & $\$ 350,000-$ & & 11.4070 \\
\hline & & & $\$ 399,999$ & 442 & $10.50 \%$ \\
\hline & & & $\$ 400,000-$ & & \\
\hline & & & $\$ 449,999$ & 356 & $8.50 \%$ \\
\hline & & & $\$ 450,000-$ & & \\
\hline & & & $\$ 499,999$ & 122 & $2.90 \%$ \\
\hline & & & $\$ 500,000-$ & & \\
\hline & & & $\$ 549,999$ & 21 & $0.50 \%$ \\
\hline & & & $\$ 550,000+$ & 3 & $0.10 \%$ \\
\hline & & & Total number & 4,197 & \\
\hline
\end{tabular}




\begin{tabular}{|l|l|}
\cline { 2 - 2 } & $\begin{array}{l}\text { Note: Educational debt is the sum of } \\
\text { undergraduate debt and dental school } \\
\text { debt. Percentages may not total } 100 \% \\
\text { because of rounding. }\end{array}$ \\
\hline
\end{tabular}

\begin{tabular}{|c|c|c|}
\hline \multicolumn{3}{|c|}{$\begin{array}{l}\text { Table } 5 \\
\text { Practice Location of } 2016 \text { Graduates compared to 1996-2011 PEPP } \\
\text { Participants }\end{array}$} \\
\hline Practice Location of 2016 Graduates & $\begin{array}{l}\text { Total } \\
\text { Number }\end{array}$ & Percent \\
\hline Rural community & 285 & $6.40 \%$ \\
\hline Small town & 610 & $13.70 \%$ \\
\hline Large town & 708 & $15.90 \%$ \\
\hline Mid-sized city & 1,222 & $27.50 \%$ \\
\hline Urban fringe & 852 & $19.20 \%$ \\
\hline Inner city & 334 & $7.50 \%$ \\
\hline Other & 178 & $4.00 \%$ \\
\hline Unsure & 256 & $5.80 \%$ \\
\hline Total number by group & 4,445 & \\
\hline Practice Location of PEPP Participants & $\begin{array}{l}\text { Total } \\
\text { Number }\end{array}$ & Percent \\
\hline Rural Unincorporated Area & 1 & $2 \%$ \\
\hline Small Town (less than 2,500) & 2 & $5 \%$ \\
\hline $\begin{array}{l}\text { Town }(2,500-10,000 \text { other than a } \\
\text { suburb) }\end{array}$ & 7 & $16 \%$ \\
\hline Small City (10K-50K) & 7 & $16 \%$ \\
\hline Suburb of Moderate Size City & 2 & $5 \%$ \\
\hline City of Moderate Size(50K-500k) & 12 & $27 \%$ \\
\hline Suburb of Large City & 5 & $11 \%$ \\
\hline Large City( 500k or more) & 8 & $18 \%$ \\
\hline Total numbers: & 44 & \\
\hline
\end{tabular}




\begin{tabular}{|c|c|c|}
\hline $\begin{array}{l}\text { Table } 6 \\
\text { Payer compositio } \\
\text { that }\end{array}$ & $\begin{array}{l}\text { of PEPP program participants' } \\
\text { new independent dentists su }\end{array}$ & $\begin{array}{l}\text { practice }(n=44) \text { compared with } \\
\text { veyed nationally }{ }^{14}\end{array}$ \\
\hline Payer Type & $\begin{array}{l}\text { PEP Program Participants } \\
\text { (mean \%) }\end{array}$ & $\begin{array}{l}\text { New Independent Dentists' } \\
\text { (mean \%) }\end{array}$ \\
\hline Private insurance & $16 \%$ & $63 \%$ \\
\hline Medicaid & $42 \%$ & $9 \%$ \\
\hline Self-pay & $33 \%$ & $28 \%$ \\
\hline Pro & & \\
\hline Bono/Reduced & & \\
\hline fee & $9 \%$ & $\mathrm{~N} / \mathrm{a}$ \\
\hline
\end{tabular}

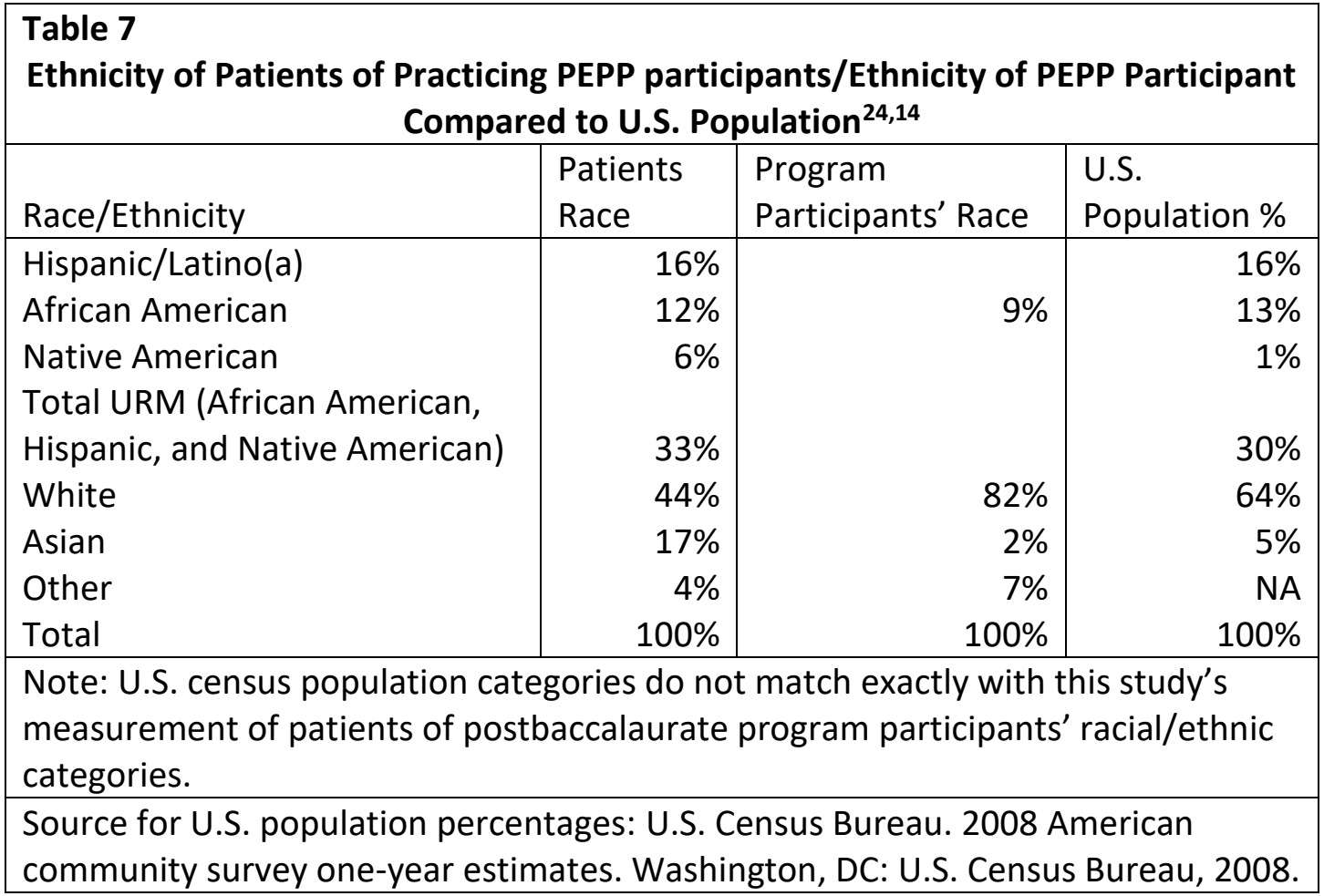




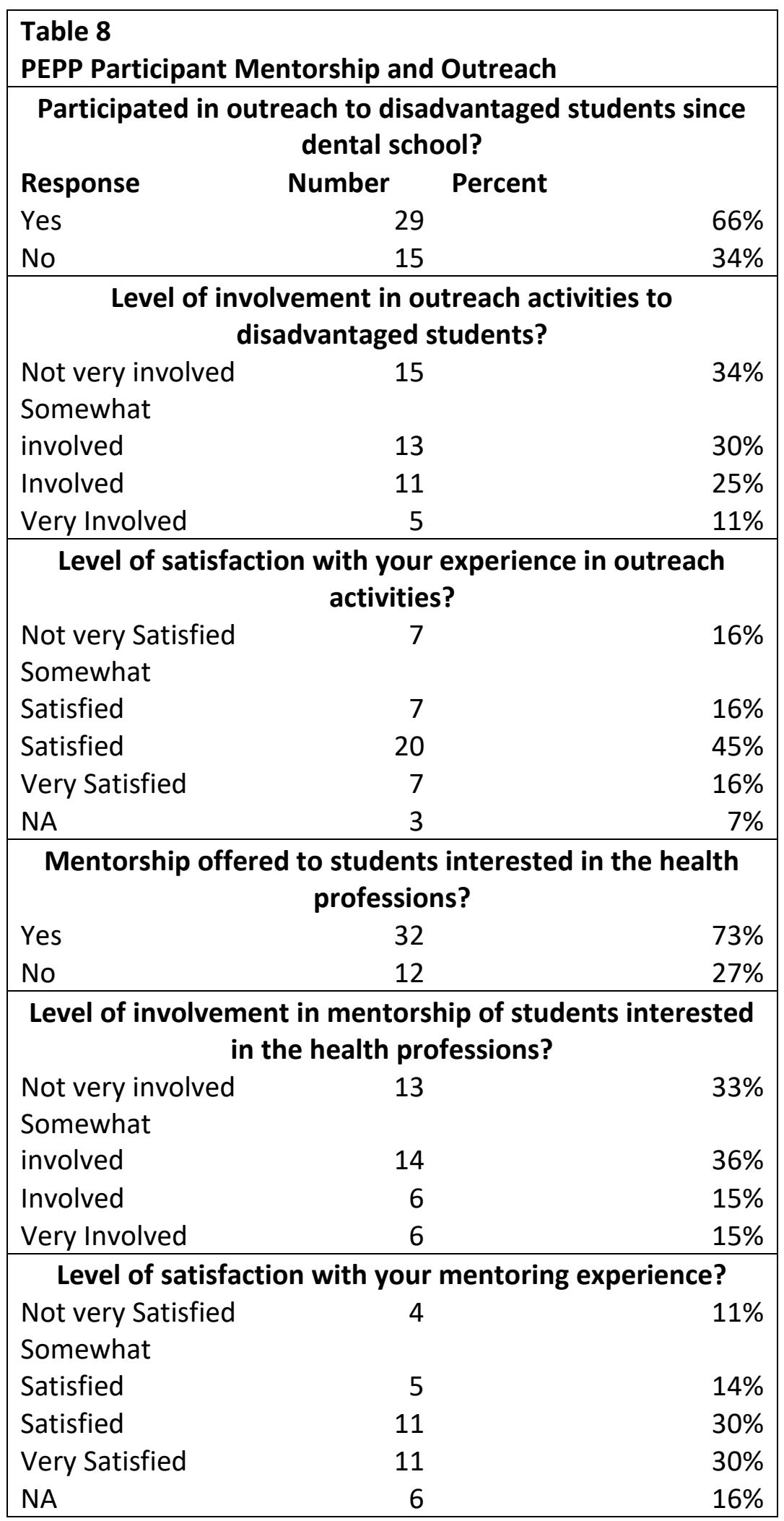




\begin{tabular}{|lcc|}
\hline \multicolumn{3}{|l|}{$\begin{array}{l}\text { Table } 9 \\
\text { Is The Practice Located in Kentucky? }\end{array}$} \\
\hline Yes & 26 & $60 \%$ \\
No & 17 & $40 \%$ \\
\hline If Yes, is Practice in an Underserved County? \\
\hline Yes & 5 & $19 \%$ \\
No & 21 & $81 \%$ \\
\hline
\end{tabular}


APPENDIX

SURVEY INSTRUMENT

\section{Long-Term Outcomes of the Professional Education Preparation Program: Increasing Diversity and Access to Dental Care Date}

You are being invited to participate in a research study by answering the attached survey about the long-term outcomes of the Professional Education Preparation Program and the influence that PEPP participants have had as a practitioner and member of the community. There are no known risks for your participation in this research study. The information collected may not benefit you directly. The information learned in this study may be helpful to others. The information you provide will be used to gage the efficacy of PEPP increasing diversity among dental school student populations and dental practitioners as well as increasing access to dental care compared with national statistics. Your completed survey will be stored at The University of Louisville School of Dentistry School of Dentistry, $501 \mathrm{~S}$. Preston St., Room 133B. The survey will take approximately 20 minutes time to complete.

Individuals from the Department of General Dentistry and Oral Medicine \& The Office of Diversity and Inclusion and other regulatory agencies may inspect these records. In all other respects, however, the data will be held in confidence to the extent permitted by law. Should the data be published, your identity will not be disclosed.

Taking part in this study is voluntary. By completing this survey you agree to take part in this research study. You do not have to answer any questions that make you uncomfortable. You may choose not to take part at all. If you decide to be in this study you may stop taking part at any time. If you decide not to be in this study or if you stop taking part at any time, you will not lose any benefits for which you may qualify.

If you have any questions, concerns, or complaints about the research study, please contact: Dr. Sherry Babbage, 502-852-6121.

If you have any questions about your rights as a research subject, you may call the Human Subjects Protection Program Office at (502) 852-5188. You can discuss any 
questions about your rights as a research subject, in private, with a member of the Institutional Review Board (IRB). You may also call this number if you have other questions about the research, and you cannot reach the research staff, or want to talk to someone else. The IRB is an independent committee made up of people from the University community, staff of the institutions, as well as people from the community not connected with these institutions. The IRB has reviewed this research study.

If you have concerns or complaints about the research or research staff and you do not wish to give your name, you may call 1-877-852-1167. This is a 24-hour hot line answered by people who do not work at the University of Louisville.

Sincerely,

Dr. Sherry Babbage

\section{Samuel Petersen}

\section{Professional Education Preparation Program Participant Survey}

1. Please fill in the blank or circle the most appropriate answer

2. In what class year did you participate in PEPP?

3. Is English your first language?

Yes

No

4. Do you have a first language other than English or in addition to English?

Yes

No

5. If you have a first language other than English, please list your first language(s) below. 
6. Please list the languages that you use in your practice other than ENGLISH:

7. What is your ethnicity? (Please circle one)

Caucasian

African American

Chinese

Filipino

Hispanic

Japanese

Korean

Middle Eastern

Native American

Pacific Islander

South East Asian

Vietnamese

Other (Please specify)

8. If you were not born in the United States, how long have you lived here?
A. Less than 5 years
B. $5-10$ years
C. Longer than 10 years
D. I was born in the US

9. What are your parents' highest levels of completed education? Mother:
A. Did not graduate high school
B. High school 

C. Some college
D. Four-year College or university
E. Graduate or professional school

Father:
A. Did not graduate high school
B. High school
C. Some college
D. Four-year College or university
E. Graduate or professional school

10. How did you pay for your undergraduate program? (List percent to total sum of $100 \%$ ) Grant or scholarship: Loans:

Work-study program:

Personal income:

Money from parents/family:

Money earned by spouse:

Total:

11. How did you pay for the Dental program? (List percent to total sum of $100 \%$ ) Grant or scholarship:

Loans:

Work-study program:

Personal income:

Money from parents/family: 
Money earned by spouse:

Total:

12. How much debt did you have upon graduating from dental school?
A. $\$ 1-\$ 30,000$
B. $\$ 30,001-\$ 74,999$
C. $\$ 75,000-\$ 150,000$
D. $150,001-\$ 300,000$
E. Other amount (Please specify):
F. None

13. How much debt did do you have now?
A. $\$ 1-\$ 30,000$
B. $\$ 30,001-\$ 74,999$
C. $\$ 75,000-\$ 150,000$
D. $\$ 150,001-\$ 300,000$
E. Other amount (Please specify):
F. None

14. To which dental schools did you apply?

School 1:

School 2:

School 3:

School 4:

School 5:

School 6:

School 7: 
School 8:

15. Which dental school did you ATTEND?

Why?
A. Program reputation
B. Geographic location
C. Clinical training sites
D. Cost
E. Program features
F. Program support
G. School outreach/recruitment efforts
H. Know someone there
I. Advised/Counseled
J. Family/partner/spouse needs
K. Other (Please specify)

16. Did you complete any preceptor-ships, clinical rotations, or electives working with the medically underserved populations while in dental school?

Yes

No

17. Did you speak a language other than English with this population? If yes, please specify.

Yes

No

Please Specify: 
18. Did you provide any volunteer and /or community service DURING dental school?

Yes

No

If yes, how involved were you in your volunteer and/or community service DURING dental school?
A. Very involved
B. Involved
C. Somewhat involved
D. Not very involved

19. How satisfied were you with your volunteer or community service experience?

Very satisfied

Satisfied

Somewhat satisfied

Not very satisfied

20. When did you pass your National Boards part 1 ?

First attempt

Second attempt

More than 2 attempts

21. When did you pass your National Boards part 2?

First attempt

Second attempt

More than 2 attempts 
22. Are you currently working as a dentist?

Yes

No

23. Where are you practicing NOW?
A. Large city (Population 500K or more)
B. Suburb of large city
C. City of moderate size $(50 \mathrm{~K}-500 \mathrm{~K})$
D. Suburb of moderate sized city
E. Small city (10K - 50K other than a suburb)
F. Town $(2,500-10,000$ other than a suburb)
G. Small town (population less than 2,500)
H. Rural/Unincorporated area
Other (Please specify)

24. Please list the zip code(s) for your CURRENT place(s) of practice

Practice 1:

Practice 2:

Practice 3:

Practice 4:

25. Do you work with an underserved population?

Yes

No

26. Were you interested in working with an underserved population after dental school? Yes 
27. Are you working in a predominantly non-English speaking community? If yes, please specify the language used.

Yes (Please specify the language used.)

No

28. Please estimate the composition of your patients' coverage by payer type in your PRIMARY practice.

(Total should add up to $100 \%$ )

Private Payer:

Insurance:

Medicaid:

Pro-bono/Reduced Fee:

Total:

29. Please estimate the ethnic composition of the CURRENT patient population in your PRIMARY practice.

(Total should add up to $100 \%$ )

Caucasian

African American

Chinese:

Filipino:

Hispanic:

Japanese:

Korean:

Middle Eastern:

Native American: 
Pacific Islander:

South East Asian:

Vietnamese:

Other (Please specify):

Total:

30. How many employees do you have?

31. Would you say that the majority of your office staff received their primary training:

In house

Tech program

Undergraduate degree

Graduate degree

Trained at another office

32. What are your career interests? (Circle all that apply)

Periodontics

General Practice

Endodontic

Orthodontics and Dentofacial Orthopedics

Dental Public health

Oral and Maxillofacial Pathology

Oral and Maxillofacial Radiology

Oral and Maxillofacial Surgery

Pediatric Dentistry

Prosthodontics

Other (Please specify) 
33. What \% out of all of your procedures would you estimate are:

Preventive/Restorative:

Cosmetic:

34. Do you plan to work primarily with racial or ethnic minority populations in the future?

Yes

No

35. Have you taken part in any activities where you offer outreach to minority or disadvantaged students SINCE dental school?

$$
\begin{aligned}
& \text { Yes } \\
& \text { No }
\end{aligned}
$$

36. How would you describe your level of involvement in outreach activities to minorities or disadvantaged students?
A. Very involved
B. Involved
C. Somewhat involved
D. Not very involved

37. How satisfied are you with your experience in outreach activities?

Very satisfied

Satisfied

Somewhat satisfied

Not very satisfied

NA 
38. Do you offer any mentorship to students interested in the health professions?

Yes

No

39. How would you describe your level of involvement in mentorship of students interested in the health professions?
A. Very involved
B. Involved
C. Somewhat involved
D. Not very involved

40. How satisfied are you with your mentoring experience?

Very satisfied

Satisfied

Somewhat satisfied

Not very satisfied

NA

Comments: What role did the Professional Education Preparation Program play in your life? 


\section{ACKNOWLEDGEMENTS}

The authors would like to thank the PEPP participants for their support of the

program and participation in the study. The authors would also like to thank the team at The University of California for allowing us to utilize their survey instrument to further study access to care issues in the state of Kentucky.

\section{DISCLOSURE}

The authors disclose that there are no financial, economic or professional interests that may have influenced the design, execution or presentation of this scholarly work. 
CURRICULUM VITAE

Samuel Dee Petersen

1910 Westmoorland Way Louisville, KY -208.240.4649- sdpete04@louisville.edu

\section{Education}

University of Louisville School of Dentistry; Louisville, KY; 2014-Current; D.M.D.;

- D.M.D. Class of 2018 Candidate

- Elected Class Treasurer

University of Louisville School of Dentistry; Louisville, KY; 2015-Current; Master of Science in Oral Biology

- M.S.O.B. Class of 2018 Candidate

Idaho State University; Pocatello, Idaho; 2012-2013; Biology (Dental Prerequisites);

- Organic Chemistry/Biology Tutor

Brigham Young University-Idaho; Rexburg; 2001, 2004-2007, Idaho; Bachelor's in Business Management;

- Emphasis in Finance and Investment Banking

- Elected CFO of most successful team in the Integrated Business Core (IBC)

- Winner of a college business plan competition

\section{Research}

University of Louisville School of Dentistry; Louisville, KY; 2015-Current

- Research project assessing the effectiveness of the Kentucky (PEPP) Professional Education Preparation Program, an underserved pipeline program

Idaho State University; Pocatello, ID; 2013

- Bench/experimental organic chemistry research

- Created precursors to nanoparticles that were used in photovoltaic cell 


\section{Professional Experience}

Financial Consultant; D.A. Davidson, Pocatello, Idaho; 2010-2012

- Worked closely with clients planning and implementing investment strategies and retirement planning

- 6 months additional training on comprehensive plans in Financial Planning Department

Client Associate; Merrill Lynch; Provo, Utah; 2008-2010

- Provided customer service for clients' financial needs

- Programmed extensive models in Excel to automate \& improve portfolio analysis

- Fully registered with Series 7 and Series 66 securities licenses

\section{Volunteer and Leadership Experience}

Christian Dental Society; Jamaica, December 2016

- Traveled to St. Elizabeth, Jamaica to provide dental services for the underserved

- Placed restorations, extracted teeth and performed cleanings for those in need

Louisville American Student Dental Association; Louisville, KY; 2014-Current

- Traveled to Washington D.C. in spring of 2016 and 2017 to advocate for legislation that would be favorable for dental students and dental professionals.

Chamber of Commerce: Leadership Pocatello; Pocatello, Idaho; 2010-2011

- Elected Chair over large annual community fundraiser

- Planned, organized and executed most successful fundraiser in 20+ year history

Rotary Club; Pocatello, Idaho; 2010-2011

- Elected Events Coordinator

- Participated in the fundraising \& community service projects 